Article

\title{
Strength Development and Shrinkage of Superabsorbent Polymer Concrete with Calcium Sulfoaluminate Clinker and Shrinkage Reducing Admixture
}

\author{
Sung-Il Jeon, Dong-Hyuk Jung * ${ }^{\mathbb{C}}$, Jeong-Hee Nam and Jae-Myun Nho \\ Deparment of Sustainable Infrastructure Research Center, Korea Institute of Civil Engineering and Building \\ Technology, Goyang-Si 10223, Korea; jeonsi@kict.re.kr (S.-I.J.); archnam@kict.re.kr (J.-H.N.); \\ nhojaemyun@kict.re.kr (J.-M.N.) \\ * Correspondence: jdh88@kict.re.kr
}

check for

updates

Citation: Jeon, S.-I.; Jung, D.-H.; Nam, J.-H.; Nho, J.-M. Strength Development and Shrinkage of Superabsorbent Polymer Concrete with Calcium Sulfoaluminate Clinker and Shrinkage Reducing Admixture. Sustainability 2021, 13, 8362. https://doi.org/10.3390/su13158362

\section{Academic Editors: Mayca}

Rubio-Gámez and Ana Jiménez del Barco Carrión

Received: 26 June 2021

Accepted: 23 July 2021

Published: 27 July 2021

Publisher's Note: MDPI stays neutral with regard to jurisdictional claims in published maps and institutional affiliations.

Copyright: (c) 2021 by the authors. Licensee MDPI, Basel, Switzerland. This article is an open access article distributed under the terms and conditions of the Creative Commons Attribution (CC BY) license (https:/ / creativecommons.org/licenses/by/ $4.0 /)$.

\begin{abstract}
In this study, we analyzed the strength and shrinkage properties of concrete with three additives, superabsorbent polymer (SAP), calcium sulfoaluminate (CSA) clinker, and shrinkagereducing admixture (SRA), to verify the internal curing and shrinkage reduction effects. According to compressive strength tests, the use of SAP as an additive resulted in a slight decrease in compressive strength, whereas using $10 \%$ CSA clinker as an additive resulted in a compressive strength $8 \mathrm{MPa}$ higher than that of ordinary concrete. In the shrinkage tests, we observed the shrinkage behavior at the surface and in the middle of the concrete while exposing the surface to ambient air for 80 days. According to the results, SAP and SRA had greater shrinkage reduction effects on the concrete than CSA clinker. In particular, the shrinkage reduction rate achieved by adding SAP to the mixture was approximately $32 \%$ compared with ordinary concrete. Based on this result, we concluded that the shrinkage of the mixture reduced due to the internal curing effect (humidity adjustment within the concrete) of the SAP. In addition, the shrinkage reduction effect was maximized when we added these materials simultaneously. In particular, the shrinkage reduction rate achieved by adding SAP and SRA together was found to be approximately $69 \%$ compared with ordinary concrete. When we added CSA, SAP, and SRA to the concrete mixture, the shrinkage reduction rate was approximately $96 \%$ compared with ordinary concrete, making this the best shrinkage reduction effect achieved.
\end{abstract}

Keywords: concrete; superabsorbent polymer (SAP); calcium sulfoaluminate (CSA) clinker; shrinkage reducing admixture (SRA); internal curing

\section{Introduction}

Global warming began in the late 19th century as human activities became diversified and intensified, and there have been numerous attempts to minimize it so far. Especially in the field of civil engineering, various studies are being conducted on resource efficiency and concrete durability due to environmental destruction and resource depletion.

In particular, carbon emissions from OPC (ordinary Portland cement), which is commonly used in the construction field around the world, account for $6 \%$ of the world's man-made carbon emissions [1]. Furthermore, durability design and minimization of construction defects were some of the most effective methods for improving the sustainability of concrete structures, that have been pointed out by previous studies [2].

In Korea, pavement maintenance cost has quadrupled in 20 years, from \$255 million in 2001 to $\$ 1192$ million in 2020 [3]. In particular, one of the biggest reasons for the increasing maintenance cost of pavement is the decreased long-term durability by early-age damage. In this study, the most economical and simplest method of enhancing the durability of concrete was determined to be 'curing'.

To hydrate the non-hydrated particles in concrete, the relative humidity inside the concrete must be maintained at least $80 \%$. If the relative humidity of concrete is below 
$80 \%$ and its temperature is below $10^{\circ} \mathrm{C}$, most cement particles will stop hydrating and eventually the strength of the concrete will be degraded [4]. Therefore, a curing process is important to improve concrete performance. In general, external curing techniques, such as the application of film curing compounds, are widely used for concrete mixtures. If properly sprayed on concrete surfaces, these compounds can ensure that $80 \%$ humidity is maintained inside the concrete for approximately seven days [4]. However, subsequently, the humidity inside the concrete may drop sharply around the surface area, and the degree of hydration reaction in the concrete may be weakened.

Shrinkage occurs from the beginning of concrete setting due to the loss of moisture within the concrete after the mixing of its component materials. At this point, chemical shrinkage and autogenous shrinkage occur as the cement consumes water for hydration reactions, while plastic shrinkage occurs around the surface as moisture gets removed by the ambient air, resulting in an overall shrinkage of the mixture. As such, the internal humidity of a typical concrete mixture decreases during the initial curing process. In addition, the water in the capillary pores of the concrete evaporates under hardened conditions, resulting in drying shrinkage.

Numerous efforts have been made to improve the quality of concrete mixtures by minimizing the shrinkage that occurs immediately after the mixing process. The internal curing technique is commonly employed for maintaining the internal humidity of concrete during the initial shrinkage process by adding highly absorbent materials that contain water during the mixing process, enhancing concrete's initial crack resistance and durability at the same time.

Kohno et al. reported that by consistently supplying moisture to lightweight aggregate (LWA), the internal relative humidity within the fine capillary pore can be maintained, meaning the autogenous shrinkage of LWA concrete is less than that of normal concrete [5]. However, Jensen and Hansen pointed out that it is difficult to control the consistency when using LWA, in addition to decreased strength and elasticity modulus [6]. They proposed the addition of superabsorbent polymer (SAP) to solve this problem. Further, they suggested that adding SAP to concrete can prevent self-desiccation.

It has been shown that $1 \mathrm{~g}$ of SAP can absorb up to $1500 \mathrm{~g}$ of water; in a cement paste, $1 \mathrm{~g}$ of SAP can absorb 10-45 g of water [7]. In a concrete mixture, SAP can maintain the water it has absorbed. When the paste dries, it releases this water, conserving the humidity in the concrete via an internal curing effect. Based on this process, the addition of SAP to concrete can have three positive effects: (1) humidity regulation, (2) shrinkage mitigation, and (3) cracking reduction.

Recent studies have reported that SAP can also lead to the securing of entrained air voids and improvements in self-healing performance [8-10]. In particular, the volume of the concrete decreases when SAP releases the water it holds, while the freezing and thawing resistance can be secured due to the presence of naturally formed voids.

Further, the addition of SAP and shrinkage reducing admixture (SRA) to high-strength self-consolidating concrete (SCC) leads to considerable reductions in autogenous shrinkage and slight reductions in drying shrinkage, respectively. In other words, SAP is effective for autogenous shrinkage mitigation and SRA is effective for drying shrinkage mitigation [11]. Furthermore, studies on shrinkage properties of UHSC, in which SAP and SRA were added simultaneously, have shown that optimal addition rates for minimizing self-shrinkage and dry shrinkage are $0.3 \%$ SAP and $2 \%$ SRA [12].

At the same time, many studies have been conducted based on the application of internal curing techniques for the autogenous shrinkage mitigation of high-performance/highstrength concrete. However, only a small amount of research has focused on improving the physical properties of ordinary concrete. In addition, there has been no research on the shrinkage behavior of SAP concrete when the surface of the concrete is exposed to ambient air, which generates both plastic shrinkage and autogenous shrinkage. This is key for simulating conditions similar to actual construction site applications (concrete pavement, bridge deck overlay, etc.). 
In this study, we assessed the compression strength of concrete with the additives, SAP and SRA, and evaluated the shrinkage properties under conditions simulating actual concrete behavior. We simultaneously evaluated the performance with and without calcium sulfoaluminate (CSA) clinker, which was added for early-stage strength improvement. When evaluating the shrinkage properties, we measured the shrinkage behavior at the surface and in the center with the concrete surface exposed to ambient air.

\section{Materials and Methods}

\subsection{Materials}

The chemical proportions of ordinary Portland cement (OPC) and CSA clinker used in this study is shown in Table 1.

Table 1. Chemical proportions of binder.

\begin{tabular}{cccc}
\hline & Unit & Portland Cement & CSA Clinker \\
\hline $\mathrm{SiO}_{2}$ & $\%$ & 20.3 & 1.64 \\
\hline $\mathrm{Al}_{2} \mathrm{O}_{3}$ & $\%$ & 4.21 & 12.0 \\
\hline $\mathrm{Fe}_{2} \mathrm{O}_{3}$ & $\%$ & 3.57 & 0.50 \\
\hline $\mathrm{CaO}$ & $\%$ & 61.4 & 61.1 \\
\hline $\mathrm{MgO}$ & $\%$ & 3.466 & 1.19 \\
\hline $\mathrm{SO}_{3}$ & $\%$ & 2.1 & 20.4 \\
\hline $\mathrm{Blains}$ & $\mathrm{cm}^{2} / \mathrm{g}$ & 3620 & 3984 \\
\hline Density & $\mathrm{g} / \mathrm{cm}^{3}$ & 3.15 & 2.85 \\
\hline $\begin{array}{c}\text { Eq. Alkali content } \\
(\mathrm{Na} O\end{array}$ & $\%$ & 0.73 & 0.33 \\
\hline Loss of ignition & $\%$ & 3.25 & 1.6 \\
\hline
\end{tabular}

The SAP used in this study was purchased from L Company; Figure 1 shows its particle size distribution and particle shape. The particle size of the SAP ranged from 30-350 $\mu \mathrm{m}$, with an average particle size of $163 \mu \mathrm{m}$. Figures 2 and 3 shows scanning electron microscopy (SEM) photographs of the SAP in dry and wet conditions. As shown in the figure, SAP particles were angulated via the grinding process. After absorbing water, the SAP expanded and we could identify the shapes presumed to indicate cross-linking and water-filled cavities.

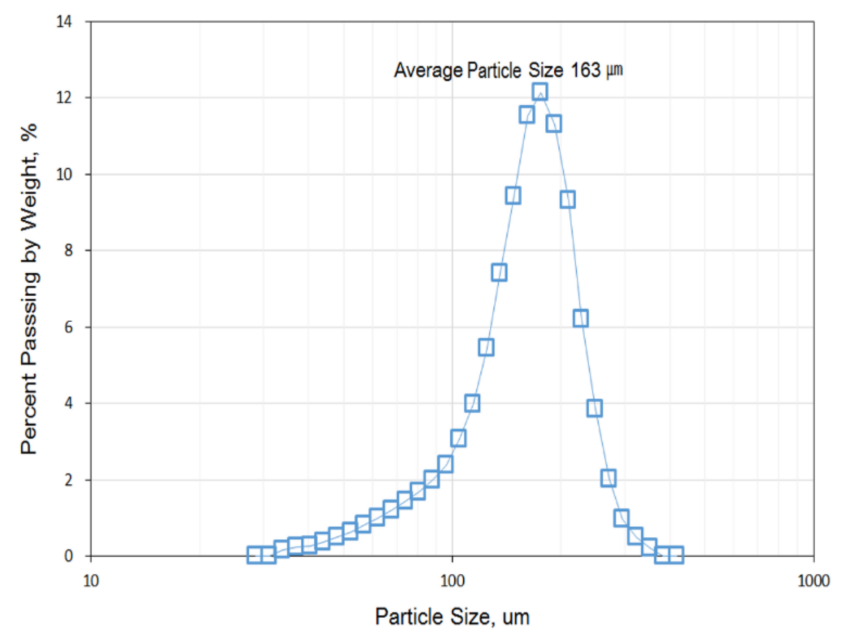

Figure 1. SAP particle size distribution. 


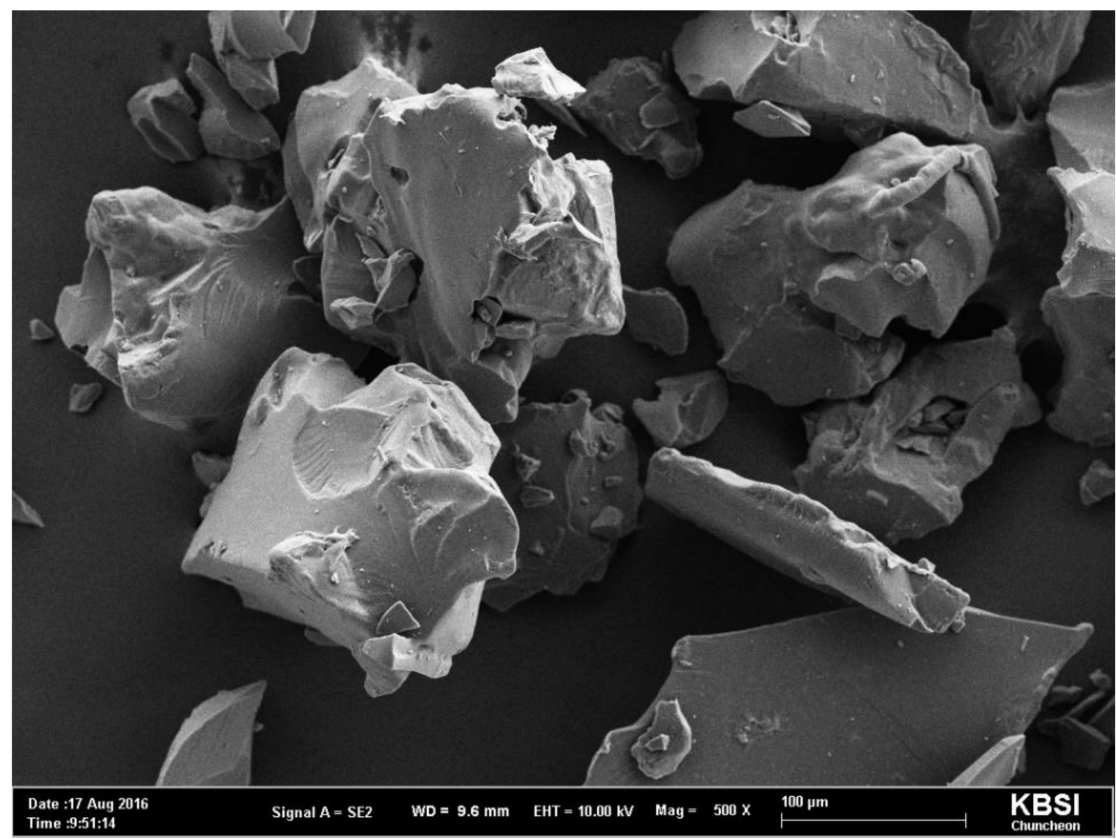

Figure 2. Shape of dry condition (SAP).

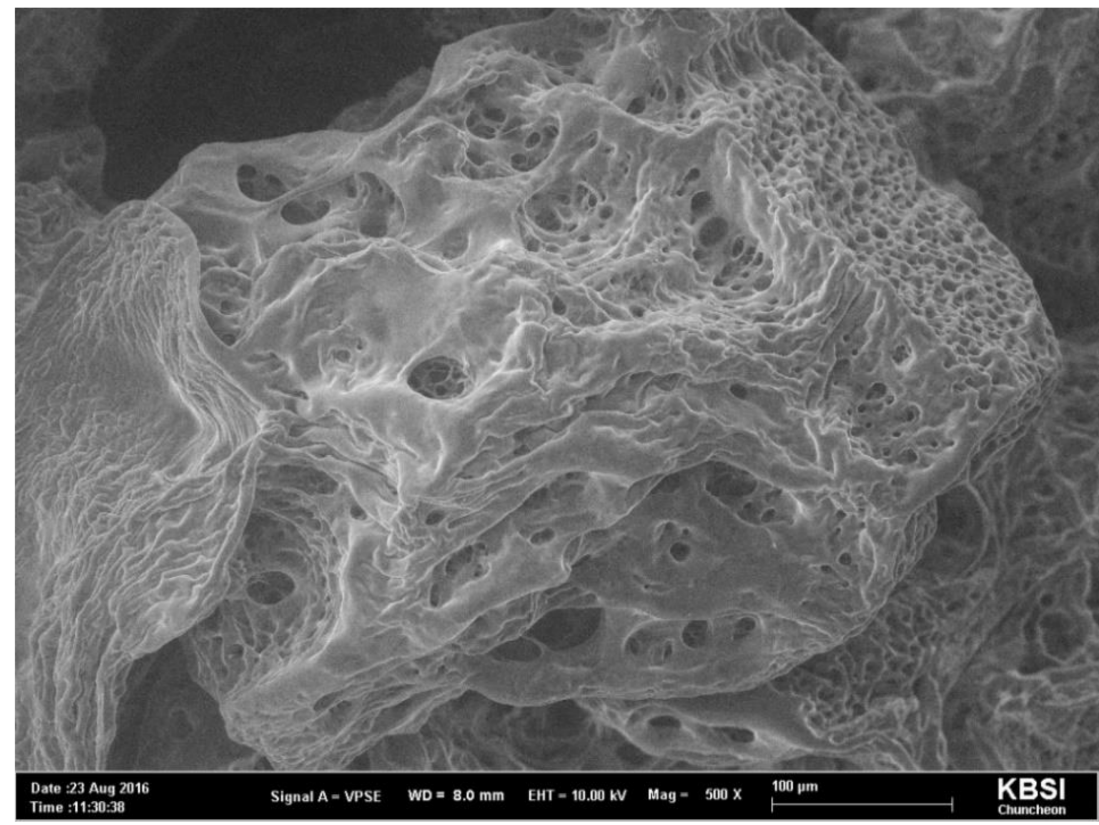

Figure 3. Shape of wet condition (SAP).

Both the coarse and fine aggregates used in this study were crushed, and the physical properties and particle size distribution of each aggregate are shown in Table 2 and Figure 4, respectively.

Table 2. Physical properties of the aggregate.

\begin{tabular}{ccccc}
\hline Type & Size $\mathbf{( m m )}$ & $\begin{array}{c}\text { Specific Gravity } \\
\left(\mathbf{g} / \mathbf{c m}^{\mathbf{3}}\right)\end{array}$ & $\begin{array}{c}\text { Absorption } \\
\text { Rate } \mathbf{( \% )}\end{array}$ & $\begin{array}{c}\text { Fineness } \\
\text { Modulus }\end{array}$ \\
\hline Fine Aggregate & $\leq 5$ & 265 & 0.87 & 3.40 \\
\hline Coarse Aggregate & $\leq 13$ & 270 & 0.65 & 6.10 \\
\hline
\end{tabular}




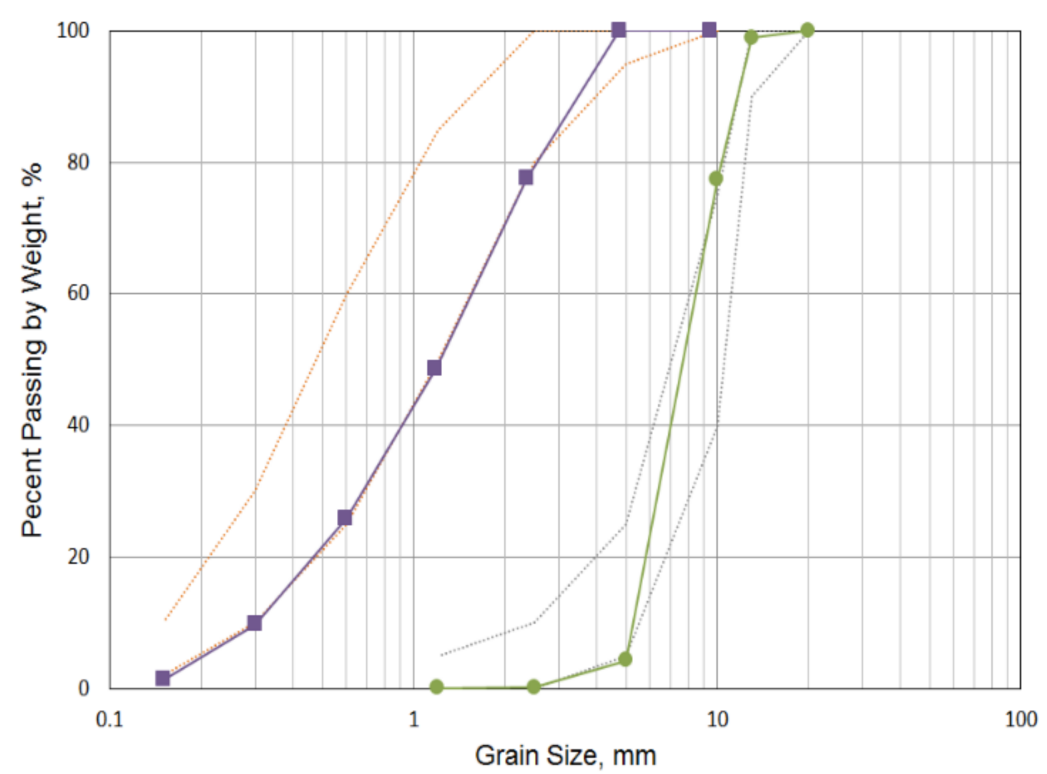

Figure 4. Particle size distribution of fine and coarse aggregate.

\subsection{Mix Proportions}

According to a study by Roh et al., evaluating the compressive strength and wear resistance of concrete in line with the SAP addition ratio, the addition of SAP at $0.9 \%$ of the binding material weight led to the best performance [13]. In the present study, we used the same type of SAP as in their study and we fixed the addition ratio to $0.9 \%$. Typically, the effect of SAP on the internal curing and physical properties of concrete depends on the particle size distribution and absorption rate of SAP. In contrast to the results of the study by Mechtcherine and Reinhardt, the SAP used in the present study was found to absorb water at only 4.5 times its own weight under the cement concrete mixture environment [7]. This is considerably less than the rates determined in previous studies, which have tended to range from 10-45 times the SAP's own weight.

Some previous studies on SAP addition ratios found that the SAP addition ratio tends to be between $0.2 \%$ and $0.6 \%[6,14-16]$, while the SAP used in the Roh et al. study had a small water absorption rate, resulting in an increase in the optimal SAP ratio [13]. Water absorption ability can be decreased in high alkali environments. In particular, the low water absorption capacity of SAP derived from this study compared to other literatures is believed to be attributable to cement and chemical admixture used in the experiment. It is believed that further research will be needed.

In the present study, we fixed the SRA addition rate at $1 \%$ relative to the binding material weight and set the CSA addition rate at $10 \%$ relative to the binding material weight. In addition, when combining the concrete with SAP or SRA, we set the water-binding material ratio at 0.43 . When using CSA, we set the ratio at 0.45 to achieve the same slump. As the powder level of CSA is higher than that of Portland cement, we used a different amount of water for the mixtures with CSA than that used in previous studies. In general, we set the total density of the binding material at $400 \mathrm{~kg} / \mathrm{m}^{3}$ and the superplasticizer (SP) addition ratio at $1.2 \%$ of the binding material weight. The addition ratio of air-entrained (AE) agent was set at $0.42 \%$ relative to the $\mathrm{SP}$ weight.

Table 3 shows the concrete mixture design followed in this study. We conducted the experiments using seven concrete mixtures, which included the addition of SAP alone, the simultaneous addition of SAP and SRA, and the simultaneous addition of CSA and other additives. 
Table 3. Concrete mixture design.

\begin{tabular}{|c|c|c|c|c|c|c|c|c|c|c|c|c|}
\hline \multirow{3}{*}{ Variables } & \multirow{3}{*}{ W/B } & \multirow{3}{*}{$\begin{array}{l}\text { S/a, } \\
\%\end{array}$} & \multicolumn{7}{|c|}{ Unit Weight } & \multirow{3}{*}{$\begin{array}{l}\text { SP, } \\
\%\end{array}$} & \multirow{3}{*}{$\underset{\%}{\mathrm{AE},}$} & \multirow{3}{*}{$\underset{\%}{\text { SRA }}$} \\
\hline & & & \multirow{2}{*}{ Water } & \multirow{2}{*}{$\begin{array}{c}\text { IC } \\
\text { Water }\end{array}$} & \multicolumn{3}{|c|}{ Binder } & \multirow{2}{*}{ Sand } & \multirow{2}{*}{ Gravel } & & & \\
\hline & & & & & Cement & SAP & CSA & & & & & \\
\hline OPC & 0.43 & 55 & 172 & - & 400 & - & - & 923 & 773 & & & - \\
\hline SAP & 0.43 & 55 & 172 & 16 & 396.4 & 3.6 & - & 920 & 770 & & & - \\
\hline $\mathrm{SAP}+\mathrm{SRA}$ & 0.43 & 55 & 172 & 16 & 396.4 & 3.6 & - & 920 & 770 & & & 1 \\
\hline CSA & 0.45 & 55 & 180 & - & 360 & - & 40 & 910 & 762 & 1.2 & 0.42 & - \\
\hline $\mathrm{CSA}+\mathrm{SRA}$ & 0.45 & 55 & 180 & - & 360 & - & 40 & 910 & 762 & & & 1 \\
\hline $\mathrm{CSA}+\mathrm{SAP}$ & 0.45 & 55 & 180 & 16 & 356.4 & 3.6 & 40 & 907 & 759 & & & - \\
\hline $\mathrm{CSA}+\mathrm{SAP}+\mathrm{SRA}$ & 0.45 & 55 & 180 & 16 & 356.4 & 3.6 & 40 & 907 & 759 & & & 1 \\
\hline
\end{tabular}

IC: internal curing; OPC: ordinary Portland cement concrete; SAP: superabsorbent polymer; CSA: calcium sulfoaluminate; SP: superplasticizer; AE: air-entrained agent; SRA: shrinkage reducing admixture

\subsection{Test Methods}

In this study, we performed slump and air flow tests with the concrete in a fresh (not hardened) state. In addition, we conducted a setting test using mortar collected via screening of the concrete mixture using a No. 4 sieve. We prepared cylindrical test pieces $10 \mathrm{~cm}$ in diameter and $20 \mathrm{~cm}$ in height to measure the compressive strength at $1,3,7$, and 28 days. The test pieces for compressive strength were subject to air-dry curing to assess the internal curing effect of the SAP.

To allow for plastic shrinkage and autogenous shrinkage to occur simultaneously after laying the concrete, we conducted our tests by modifying the method used by Kohno et al. in their autogenous shrinkage tests [5]. Figure 5 shows the shrinkage experimental model and instrumentation sections conducted in this study. In the shrinkage tests, the size of the concrete specimen was $100 \mathrm{~mm} \times 100 \mathrm{~mm} \times 400 \mathrm{~mm}$. To prevent the specimen from being restrained, we placed a Teflon sheet $(1 \mathrm{~mm}$ thick) on the bottom of the mold, a polystyrene board ( $3 \mathrm{~mm}$ thick) on both ends, and a polyester film $(0.1 \mathrm{~mm}$ thick) on top of these. Further, unlike typical autogenous shrinkage tests, in which the finished concrete surface is covered with a polyester film to suppress water evaporation, we did not cover the surface with a polyester film after finishing to allow for plastic shrinkage.
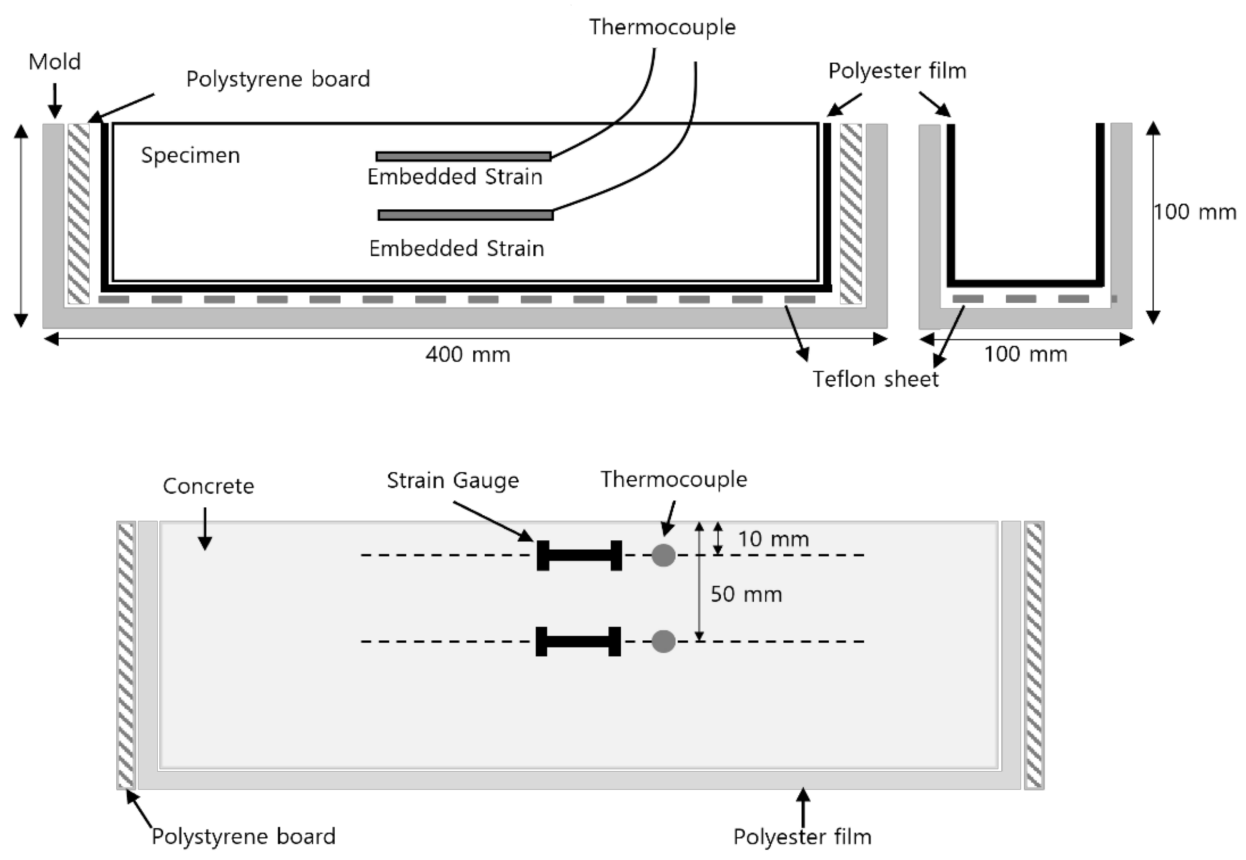

Figure 5. Cross-section of specimen for shrinkage test. 
To measure the amount of concrete shrinkage, buried strain gauges were installed inside the concrete at depths of $10 \mathrm{~mm}$ and $50 \mathrm{~mm}$ from the surface, and thermometers were installed at the same depth. The strain gauges used in this study used TML's PMFL sensor and a thermocouple from TML. PMFL is designed for the measurement of internal strain of concrete or mortar. PMFL can be embedded into the measurement position when the concrete or mortar is placed. The gauge which is used in this study was $0.09 \mathrm{~mm}^{2}$ 3-wire cross-linked vinyl leadwire of $2 \mathrm{~m}$, and the total lead wire resistance per meter was $0.4 \Omega$. These sensors were connected to a data logger (TDS-530) and monitored at intervals (10 $\mathrm{min}$ ) from concrete specimen preparation.

In this study, we used test pieces aged up to 80 days to measure the concrete shrinkage relative to different mixtures. We kept the concrete mold intact, leaving only the concrete surface exposed to the ambient air. This allowed for plastic shrinkage, autogenous shrinkage, and drying shrinkage to occur naturally in the concrete. For curing, the temperature and relative humidity were maintained at $23{ }^{\circ} \mathrm{C}$ and $50 \%$, respectively, using a constant temperature and humidity chamber.

\section{Results}

\subsection{Basic Material Properties}

In this study, we measured the slump, air content, and initial setting time for each concrete mixture. The results are shown in Table 4 . We set the target slump for the concrete mixture at $20 \mathrm{~cm}$ and the air content at 5\%. We determined the water-binding material ratio and the amounts of $\mathrm{SP}$ and $\mathrm{AE}$ agents through preliminary mixture tests. From the mixture tests, we found that most of the mixtures reached the set target shown in Table 4 . However, in the concrete mixture with SRA, the slump was approximately $17-18 \mathrm{~cm}$ and the air content was approximately $2-3 \%$, meaning neither reached its target value. For this concrete mixture, we presumed that adjusting the mixing ratio to meet the target material properties would make it difficult to perform a direct comparison of the shrinkage properties between different material mixtures. Thus, we conducted the tests under the same mixing conditions.

Table 4. Slump, air content, and initial setting time test results.

\begin{tabular}{cccc}
\hline Variables & Slump $\mathbf{( c m})$ & Air Content (\%) & Initial Setting \\
\hline OPC & 20.5 & 5.5 & $6 \mathrm{~h} 10 \mathrm{~min}$ \\
\hline SAP & 20.0 & 5.4 & $6 \mathrm{~h} 30 \mathrm{~min}$ \\
\hline SAP + SRA & 18.0 & 2.8 & $6 \mathrm{~h} 28 \mathrm{~min}$ \\
\hline CSA & 19.5 & 4.9 & $5 \mathrm{~h} 15 \mathrm{~min}$ \\
\hline CSA + SRA & 17.5 & 2.2 & $5 \mathrm{~h} 12 \mathrm{~min}$ \\
\hline CSA + SAP & 20.0 & 5.0 & $5 \mathrm{~h} 21 \mathrm{~min}$ \\
\hline CSA + SAP + SRA & 17.5 & 2.5 & $5 \mathrm{~h} 20 \mathrm{~min}$ \\
\hline
\end{tabular}

The initial setting measurements revealed that in the concrete mixture without CSA, the initial setting occurred after approximately $6 \mathrm{~h}$. In the concrete mixture with CSA, the initial setting occurred after approximately $5 \mathrm{~h}$. CSA mainly comprises ye'elimite $\left(\mathrm{C}_{4} \mathrm{~A}_{3} \mathrm{~S}\right)$, which improves early-stage strength and reduces shrinkage via expansion, as the hydration reaction of ye'elimite $\left(\mathrm{C}_{4} \mathrm{~A}_{3} \mathrm{~S}\right)$ produces ettringite $\left(\mathrm{C}_{6} \mathrm{AS}_{3} \mathrm{H}_{32}\right)$ [17]. Further, the addition of SAP tends to increase the initial setting time slightly, though this difference was insignificant. Therefore, we presumed that SRA did not considerably affect the initial setting time. We used these initial setting time results later to analyze the shrinkage characteristics. 


\subsection{Compressive Strength Test Results}

In this study, compression strength tests were used to obtain the compression strength over time. Figure 6 shows the results in relation to material age.
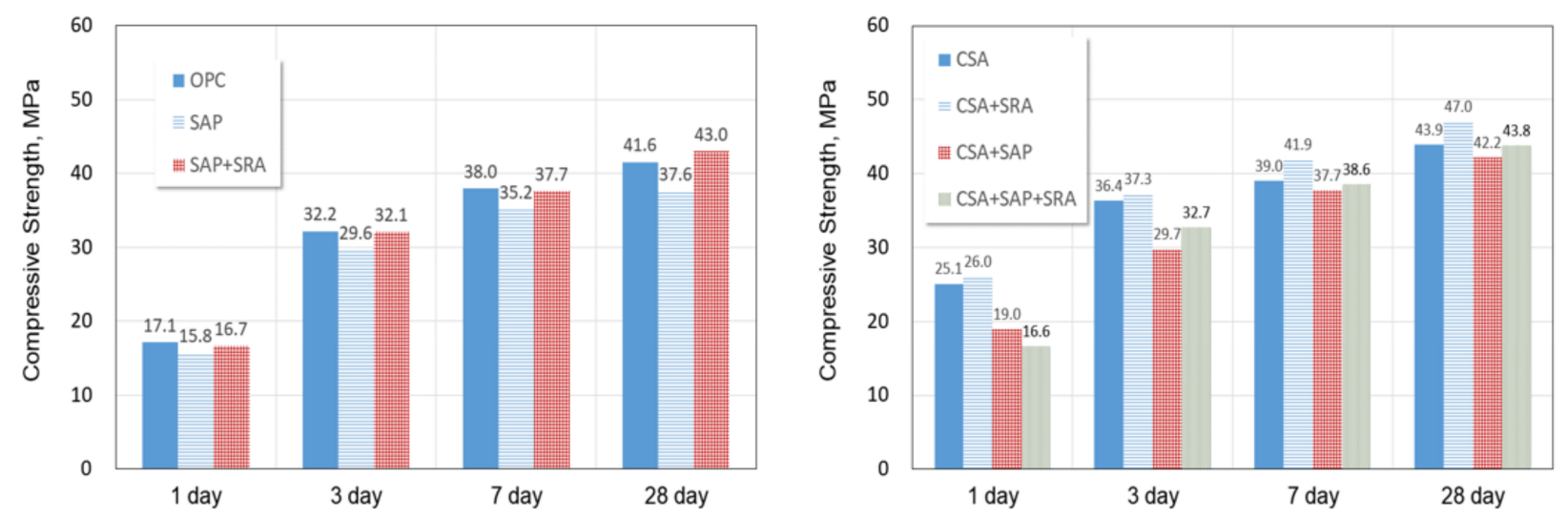

Figure 6. Compressive strength.

Comparing the OPC and CSA mixture, the compressive strength of the CSA mixture was higher by $8 \mathrm{MPa}$. For the CSA mixture, the compressive strength also exceeded $21 \mathrm{MPa}$ at the material age of one day, indicating that it meets the current standards set for trafficopening strength in Korea $(21 \mathrm{MPa})$. However, after seven days, the compressive strengths of the OPC and CSA mixtures were approximately the same. Thus, we presume that CSA is effective for early-stage strength development but not for long-term strength improvement.

In the case of the SAP mixture, its compression strength tended to be slightly less than that of the OPC mixture. Many previous studies have reported that the addition of SAP leads to an increase in the compressive strength via the internal curing effect [13,15,18-20]. However, a few other studies have reported that adding SAP can actually lead to a decrease in compressive strength [21,22]. In summary, although it is clear that the internal curing effect based on SAP leads to an increase in the density of the matrix, its effect on strength is yet to be definitively determined.

In the case of the concrete mixtures with SRA added, the compressive strength was found to increase slightly compared with those of the other mixtures. However, the SRA was not able to bring about a concrete strength enhancement effect by itself. The concrete mixtures with SRA added had a relatively low air content; as a result, their compressive strengths were higher than those of the other mixtures.

\subsection{Initial Shrinkage Feature Analysis}

In this study, we observed the concrete shrinkage over the period from immediately after laying the concrete to up to 80 days of material aging with the concrete surface exposed to ambient air. Based on this exposure, we induced plastic shrinkage, autogenous shrinkage, and drying shrinkage, similar to actual construction site behavior.

To analyze the shrinkage properties, we measured the strain behavior at the center and surface of the concrete immediately after it was laid. When analyzing the measurement data, it was important to determine the setting time because the shrinkage behavior that affects the actual hardened concrete occurs after the setting time. Yoo et al. found that, in the case of ultrahigh performance cementitious composite (UHPCC) [23], which has a low water-binding material ratio and is mixed with large amounts of fiber, the timing of autogenous shrinkage onset and initial setting time may differ. In addition, Jeon reported that an inflection in the volumetric change curve of concrete may occur when the liquid phase transforms to the stiffened phase [24].

In the present study, we compared the initial setting time with the trend of the shrinkage curve. When the initial setting time and the time at which the inflection of the curve occurred were similar, we set the inflection point time as a reference point (zero 
point) for calculating the shrinkage. If the two were considerably different, we considered the initial setting time as the reference point (zero point).

Figure 7 shows an example of the early-age behavior trend analysis. In the case of the OPC mixture, the point at which the behavior of the surface became different from that at the center was almost the same as the initial setting time. Further, in the SAP + SRA mixture, the initial setting time in the center almost coincided with the inflection point on the behavior curve. However, as there was a large difference between the initial setting time and the inflection point time in the CSA and CSA + SAP + SRA mixtures, the initial setting time was set as the reference point (zero point).
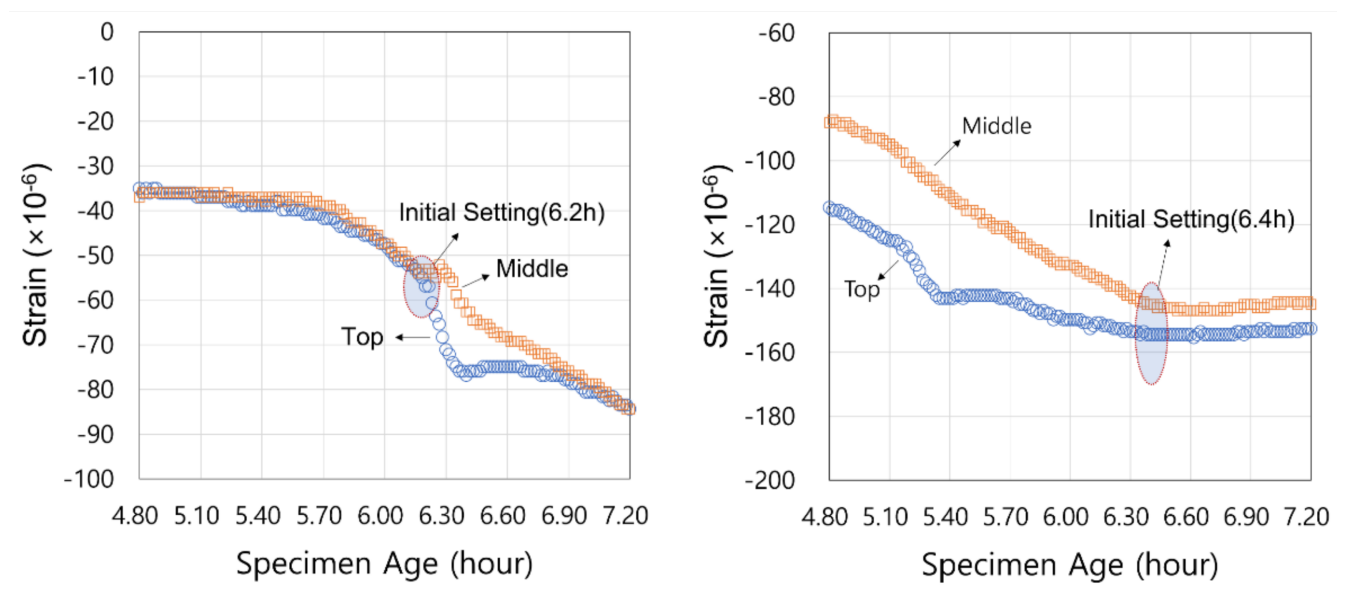

Figure 7. Example of early-age behavior analysis (left: OPC; right: SAP + SRA).

Figures 8-10 present the analysis of the three-day early-age behavior properties of the concrete mixtures without CSA clinker. The OPC mixture exhibited a considerable increase in shrinkage after the initial setting time, and the behavior became more gradual after approximately $17 \mathrm{~h}$. Further, after the first day of material aging, the shrinkage at the surface continued to increase, leading to a $73 \mu \varepsilon$ difference between the surface and middle shrinkage strains after three days. This tendency was probably due to the exposure of the concrete surface to ambient air, which allowed more moisture to evaporate from the surface. The total three-day behavior of the OPC was approximately $-270 \mu \varepsilon$ at the surface and approximately $-200 \mu \varepsilon$ in the middle.

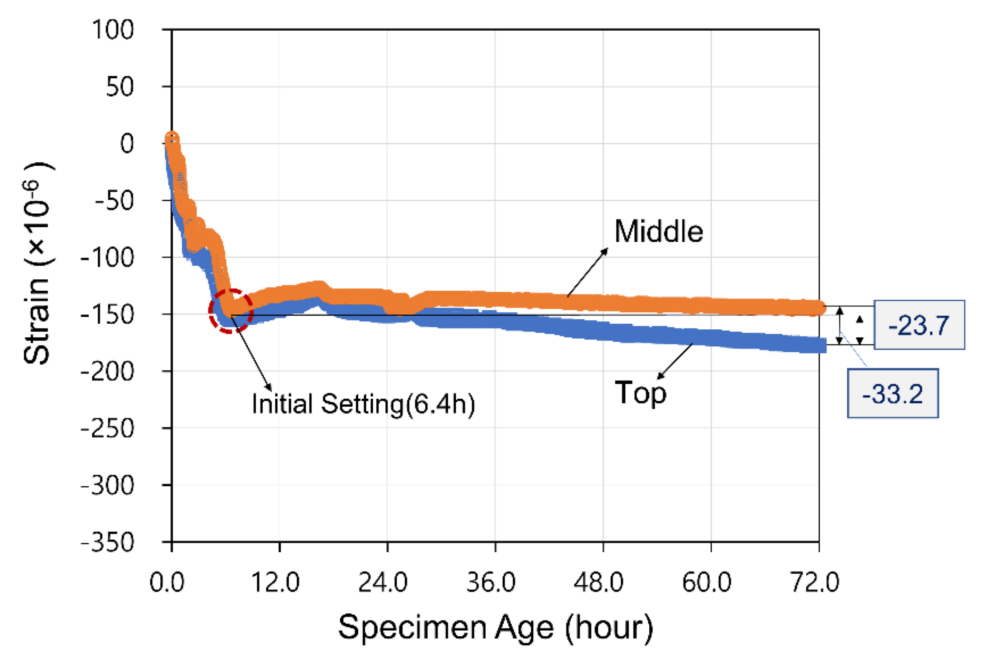

Figure 8. Early-age behavior of OPC. 


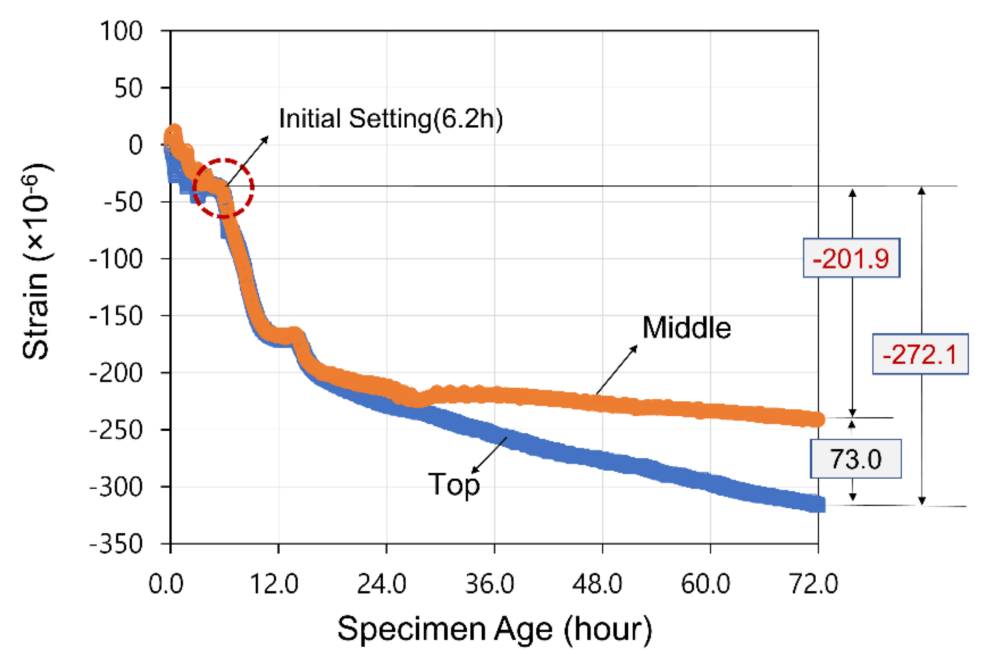

Figure 9. Early-age behavior of SAP.

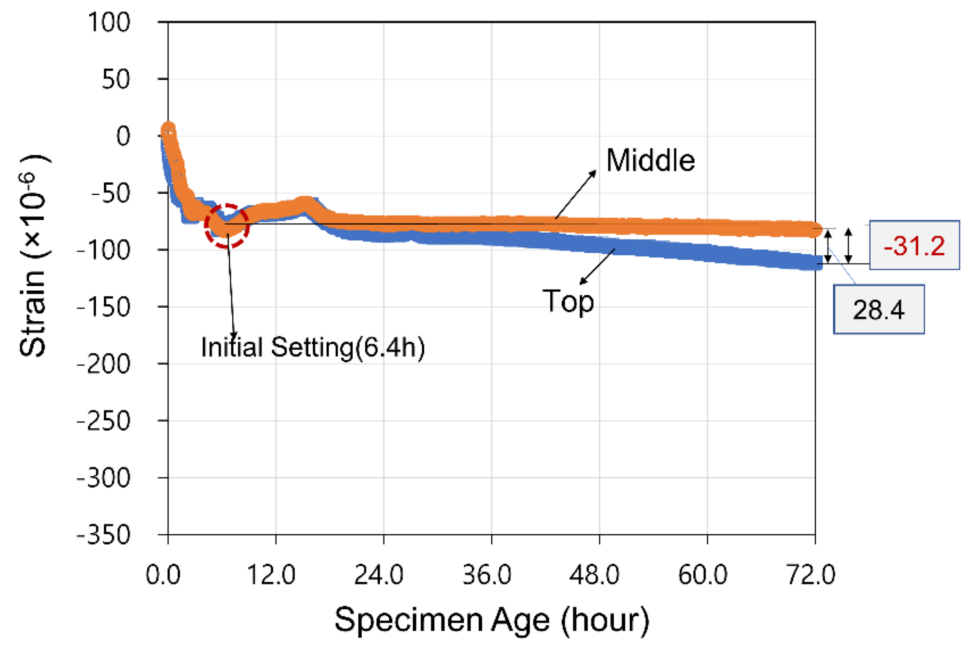

Figure 10. Early-age behavior of SAP + SRA.

In contrast, the mixture with $0.9 \% \mathrm{SAP}$ did not exhibit considerable shrinkage for three days after the initial setting time. The behavior observed after three days were $-31.2 \mu \varepsilon$ at the surface and $0 \mu \varepsilon$ at the center. The difference between the surface and middle shrinkage strains was $28.4 \mu \varepsilon$, representing notably reduced shrinkage strains compared with the OPC. This was probably caused by the addition of the SAP, which holds onto moisture in the concrete mixture and then releases this moisture to maintain the internal humidity. Therefore, the behavior of the SAP mixture was insignificant compared with that of the OPC, even though significant moisture loss occurred on the surface.

The mixture containing both SAP and SRA exhibited a similar tendency to the SAP mixture. When water loss occurs inside the concrete, surface tension occurs in the capillary pores, causing shrinkage in the concrete. If SRA is added, this surface tension decreases due to shrinkage reduction. This effect results in a significant reduction in initial shrinkage compared with the OPC.

Figures 11-14 show the analyses of the initial shrinkage properties of the mixture with CSA clinker added for three days. 


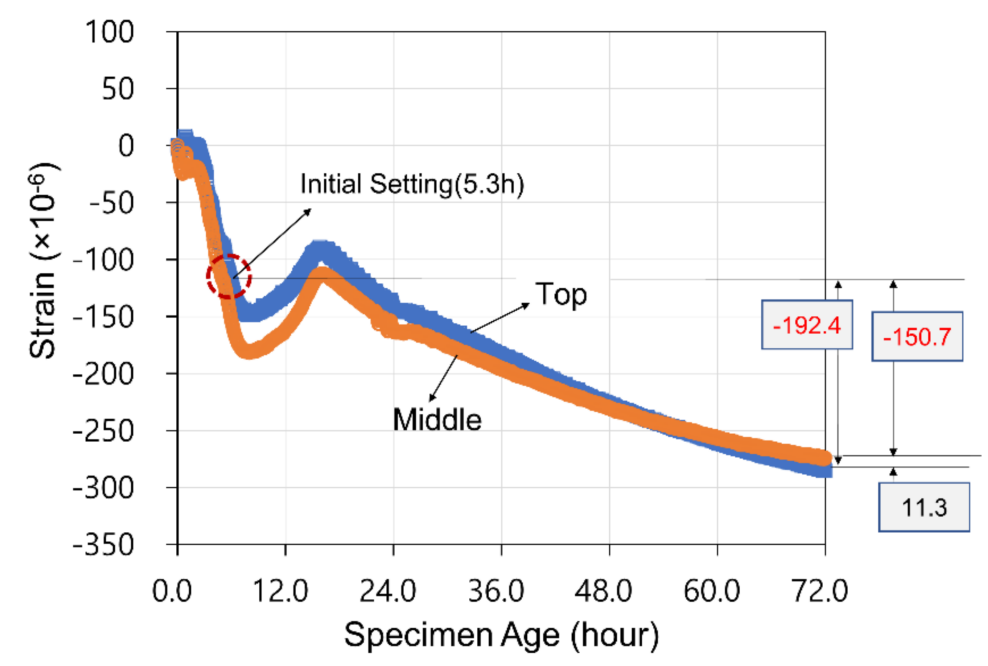

Figure 11. Early-age behavior of CSA.

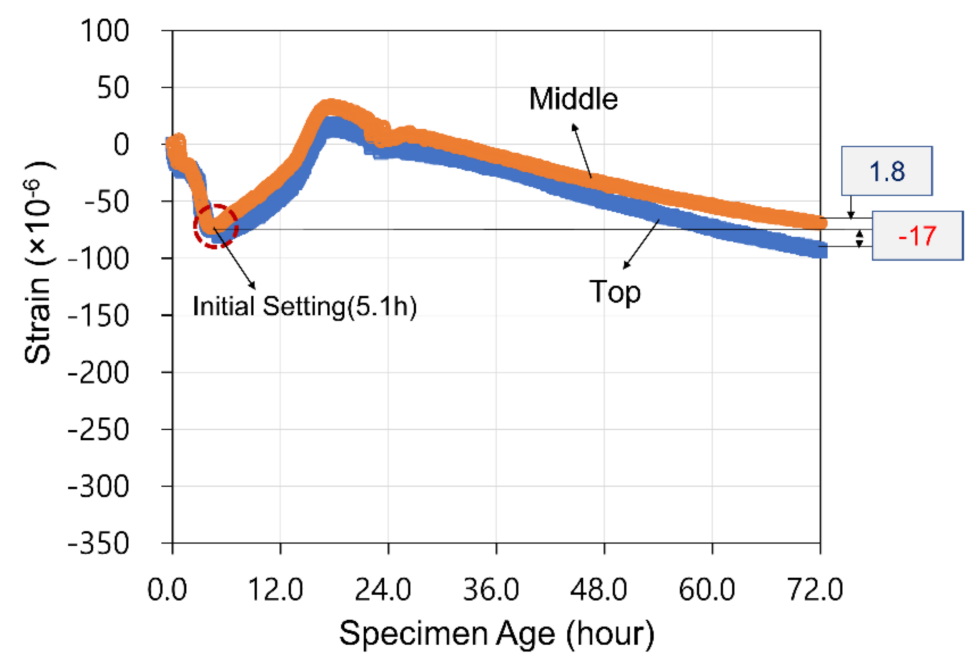

Figure 12. Early-age behavior of CSA + SRA.

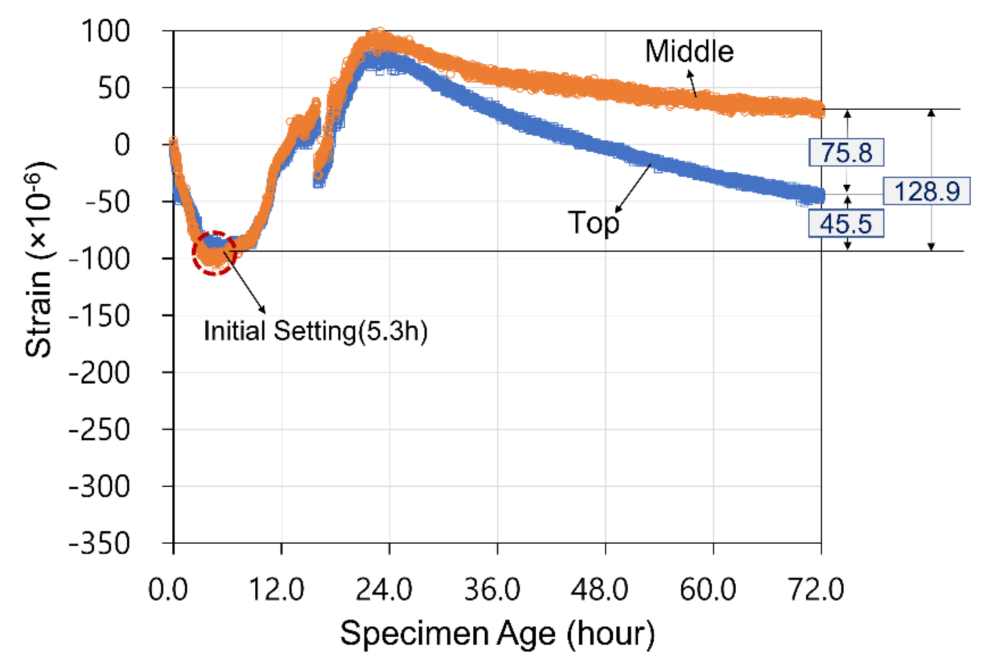

Figure 13. Early-age behavior of CSA + SAP. 


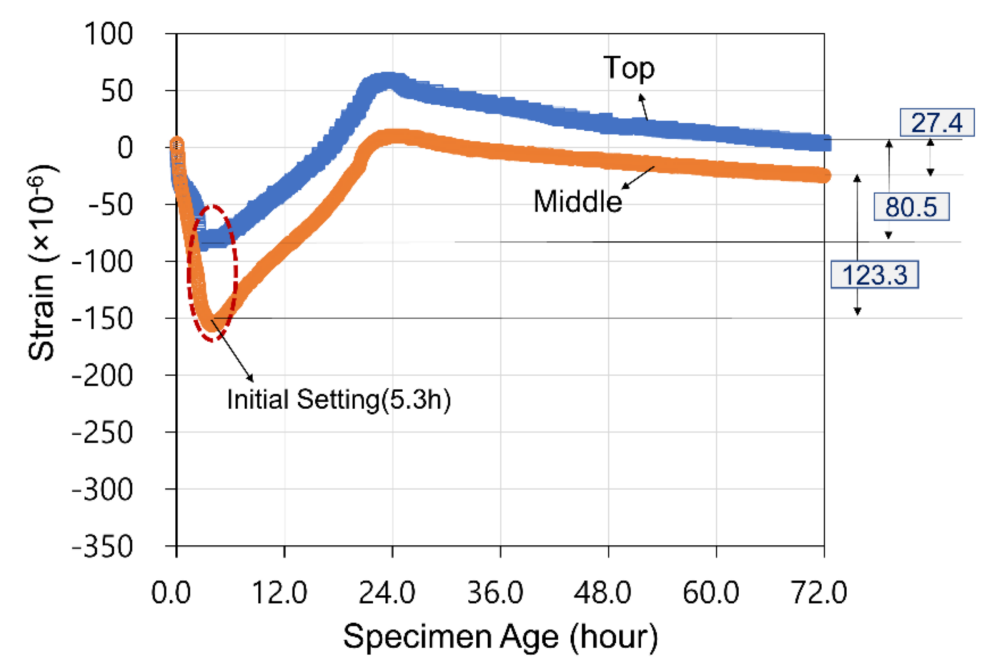

Figure 14. Early-age behavior of CSA + SAP + SRA.

Based on the trend of the shrinkage curve for the CSA mixture, an expanding behavior can be observed beginning approximately $8 \mathrm{~h}$ after laying. A peak was then reached at about $16 \mathrm{~h}$, after which the shrinkage behavior began again. This was due to the hydration reaction of ye'elimite $\left(\mathrm{C}_{4} \mathrm{~A}_{3} \mathrm{~S}\right)$, the main component of the CSA clinker, producing ettringite $\left(\mathrm{C}_{6} \mathrm{AS}_{3} \mathrm{H}_{32}\right)$, which causes expansion. The shrinkage was partially offset by the expansion behavior, reducing the middle shrinkage strain of the CSA mixture by approximately $50 \mu \varepsilon$ and the surface strain by approximately $80 \mu \varepsilon$ compared with those of the OPC mixture. In addition, when using CSA clinker, the difference between the initial surface and middle shrinkage strains was approximately $11 \mu \varepsilon$, which was quite small compared with that of the OPC mixture.

In the mixture with both CSA clinker and SRA, the transition from shrinkage behavior to expansion behavior occurred approximately $5 \mathrm{~h}$ after laying, which was almost the same as the initial setting time. In the case of the CSA mixture, the transition from shrinkage behavior to expansion behavior occurred approximately $3 \mathrm{~h}$ after the initial setting time. In the CSA + SRA mixture, this transition time was considerably advanced. Using the CSA clinker together with the SRA has been previously reported as effective in reducing shrinkage by advancing the transition from shrinkage to expansion behavior [24]. Due to this effect, the surface shrinkage strain remained at $-17 \mu \varepsilon$, though the strain in the middle was $1.8 \mu \varepsilon$, indicating an absence of shrinkage.

The mixture with both CSA clinker and SAP also exhibited a transition from shrinkage to expansion behavior similar to the initial setting time, while the transition time was considerably advanced compared with that of the CSA mixture. On the third day of material aging, the surface strain was $+45.5 \mu \varepsilon$, while the middle strain was $+128.9 \mu \varepsilon$. The difference between the surface and middle strains was $75.8 \mu \varepsilon$. As such, the expansion behavior was more notable for the CSA mixture than for the CSA + SRA mixture, and the concrete remained in an expanded state on the third day of material aging. The greater increase in expansion behavior when CSA clinker and SAP were added together is presumed to have been caused by the fact that the SAP's internal humidity retention behavior increased the reactivity of the CSA clinker, but further investigation is needed to confirm this.

In the mixture including CSA clinker, SAP, and SRA, strong expansion behavior occurred after approximately $5 \mathrm{~h}$, which is similar to the behavior of the CSA + SAP mixture. In addition, the three-day surface strain was $+80.5 \mu \varepsilon$, while the middle strain was $+123.3 \mu \varepsilon$. The difference between the surface and middle strains was $27.4 \mu \varepsilon$. As shown in Figure 11, the shrinkage behavior occurred after the expansion peak points and the decreasing curve was relatively gentle compared with that of the CSA + SAP mixture. As mentioned earlier, we presumed that the SRA reduced the surface tension of the capillary 
pores caused by water loss in the concrete, resulting in reduced shrinkage and a gentle curve.

Based on our results, CSA clinker, SAP, and SRA all appeared to be effective in reducing initial shrinkage. In particular, when SAP was added, the initial shrinkage was almost zero, thus indicating that using additional additives mixed with SAP can further maximize this effect.

Figures 15-21 show the concrete strain data observed up to 80 days. Table 5 also compares the shrinkage strain measured over 80 days among the different mixtures.

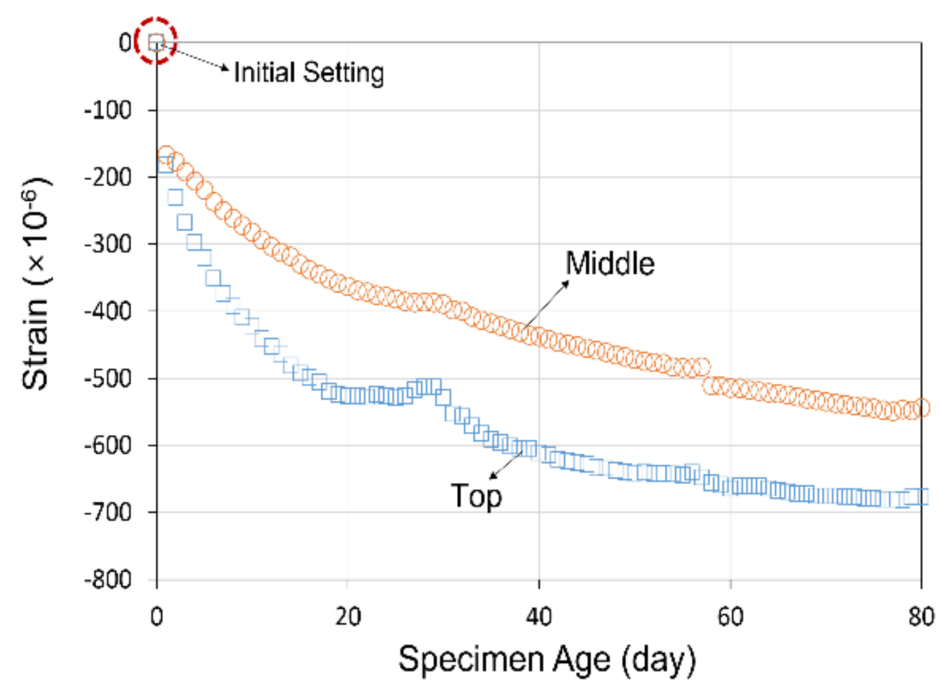

Figure 15. Long-term behavior of OPC.

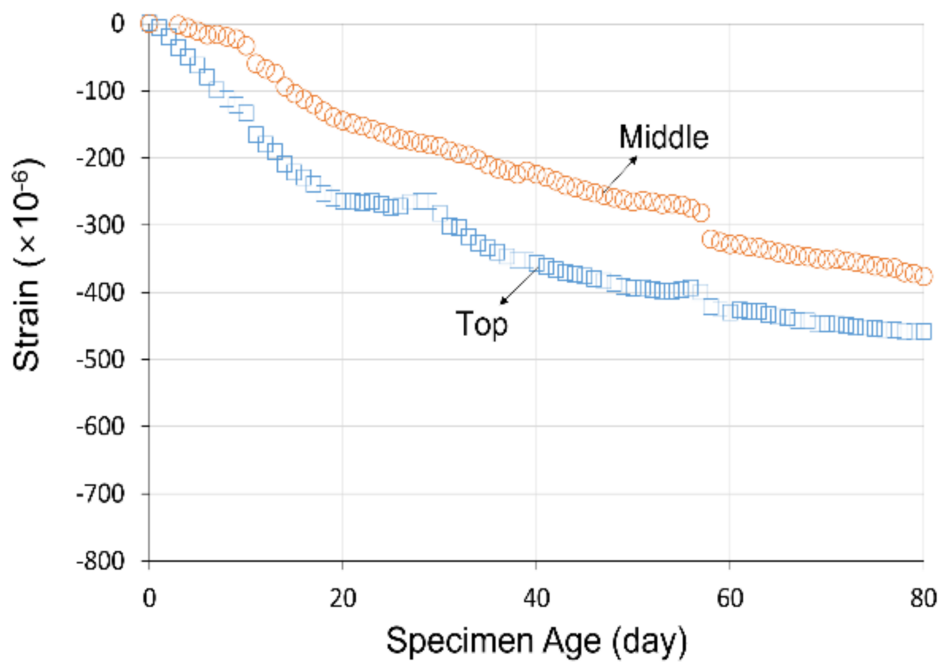

Figure 16. Long-term behavior of SAP. 


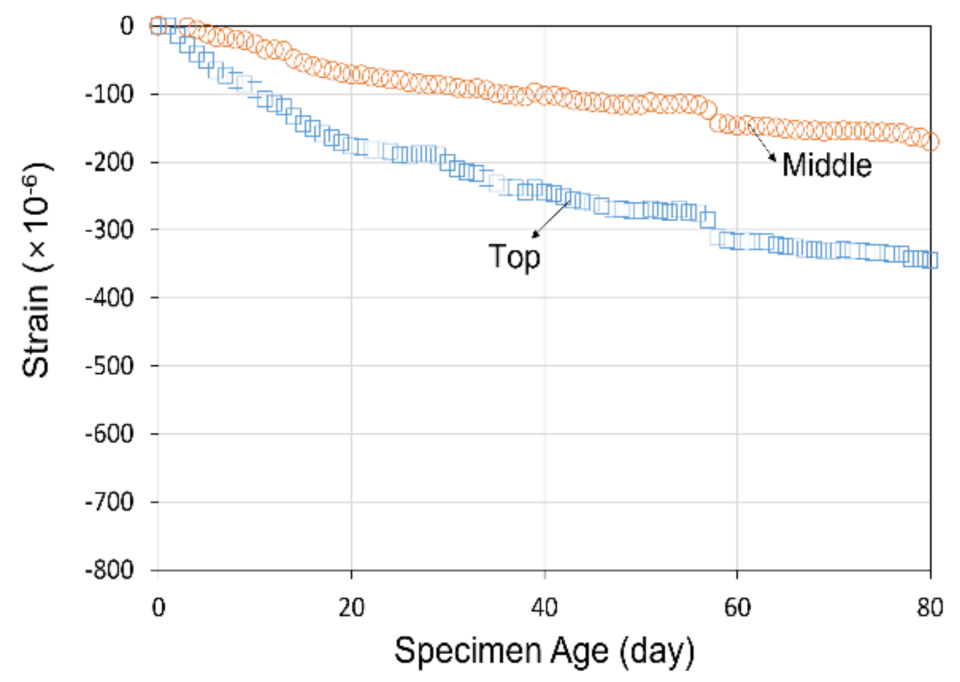

Figure 17. Long-term behavior of SRA.

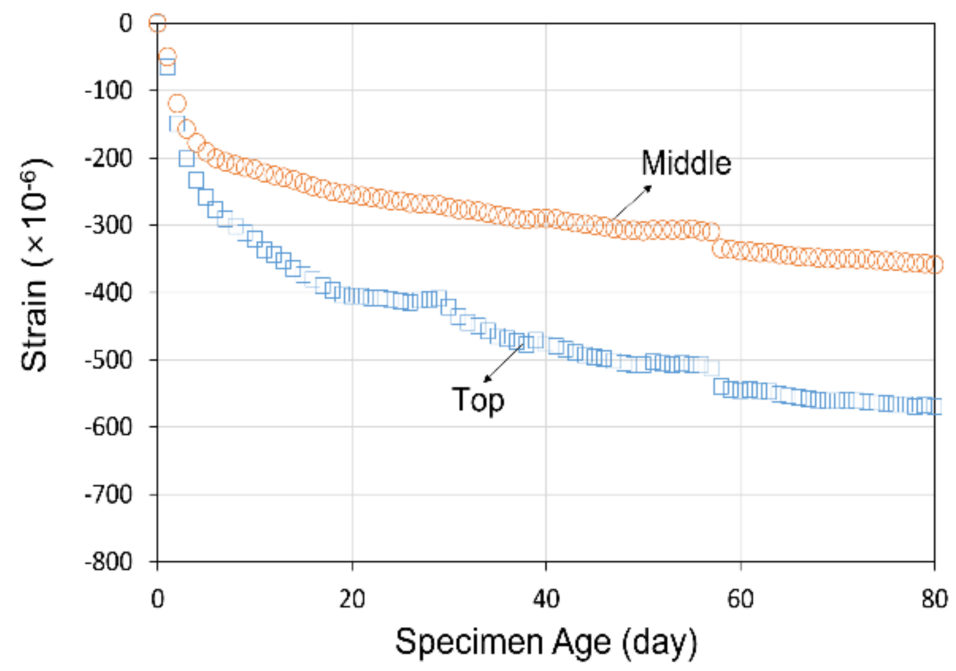

Figure 18. Long-term behavior of CSA.

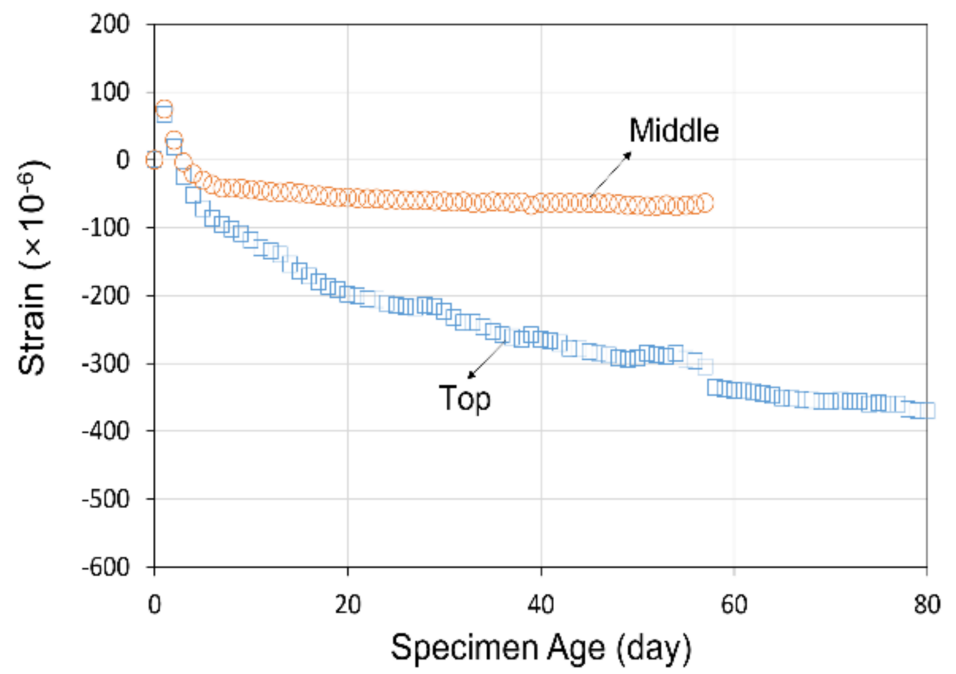

Figure 19. Long-term behavior of CSA + SRA. 


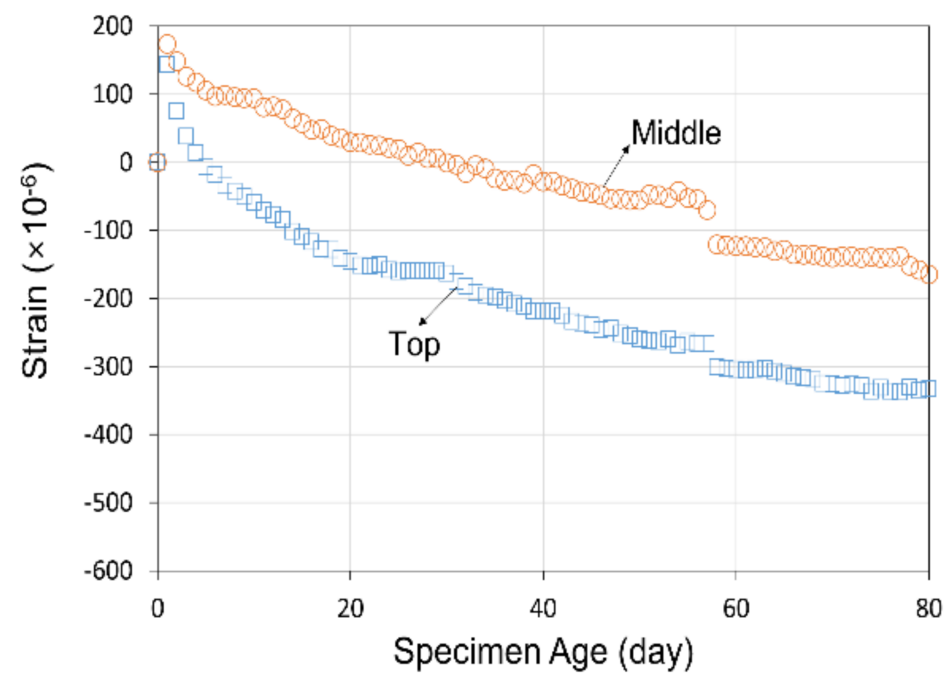

Figure 20. Long-term behavior of CSA + SAP.

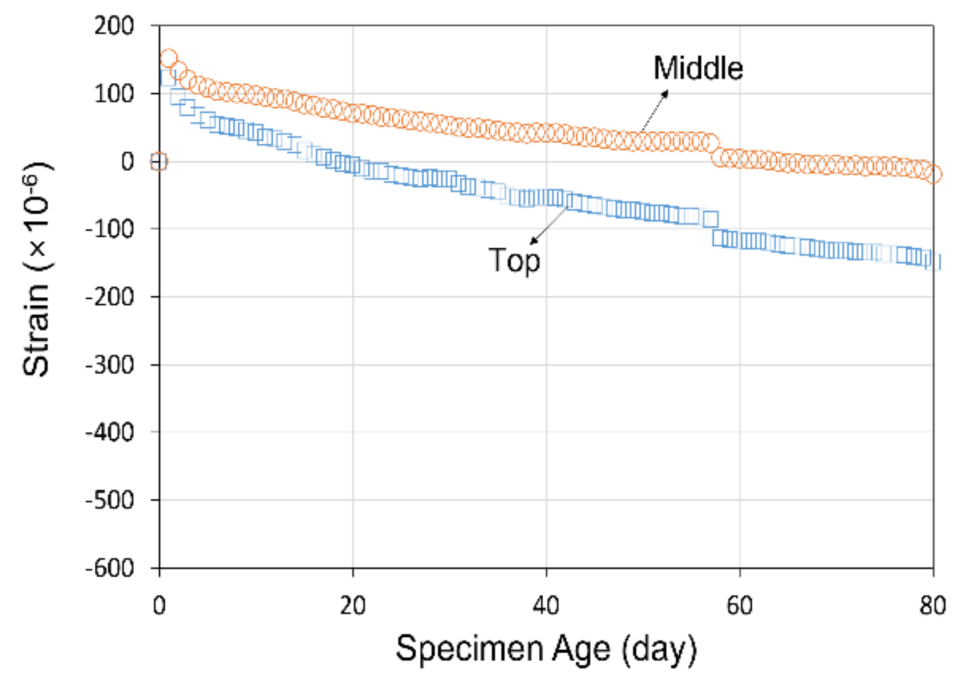

Figure 21. Long-term behavior of CSA + SAP + SRA.

Table 5. Comparison of shrinkage strains for each mixture after 80 days.

\begin{tabular}{cccccc}
\hline Variables & $\begin{array}{c}\text { Top } \\
\text { Shrinkage } \\
\text { Strain }\end{array}$ & $\begin{array}{c}\text { Middle } \\
\text { Shrinkage } \\
\text { Strain }\end{array}$ & Difference & \multicolumn{2}{c}{$\begin{array}{c}\text { Shrinkage Reduction } \\
\text { Rate Compared with } \\
\text { OPC (\%) }\end{array}$} \\
\cline { 5 - 6 } OPC & -676.8 & -544.1 & 132.7 & - & Top \\
\hline SAP & -458.7 & -372.5 & 86.2 & 32.2 & 31.5 \\
\hline SAP + SRA & -346.0 & -170.6 & 175.4 & 48.9 & 68.6 \\
\hline CSA & -569.6 & -375.3 & 194.3 & 15.8 & 31.0 \\
\hline CSA + SRA & -370.6 & & & 45.2 & \\
\hline CSA + SAP & -333.7 & -158.2 & 175.5 & 50.7 & 70.9 \\
\hline CSA + SAP + SRA & -148.8 & -18.9 & 129.9 & 78.0 & 96.5 \\
\hline
\end{tabular}

In the case of the OPC mixture, a large behavior occurred initially, and the trend of the curve was found to be moderate after 20 days. The surface shrinkage observed at an age of 80 days was $-676.8 \mu \varepsilon$, while that in the middle was $-544.1 \mu \varepsilon$, meaning this 
was the largest shrinkage among the mixtures. By comparison, when SAP was added, there was no significant movement initially, and the subsequent trend was relatively gentle. The shrinkage reduction rate achieved by adding SAP to the mixture was found to be approximately $32 \%$ compared with the OPC mixture, indicating the shrinkage was reduced based on SAP'S ability to regulate the humidity inside the concrete. In addition, for the SAP mixture, the difference in behavior between the surface and middle areas was smaller than that for OPC. This reduction in shrinkage by section depth is believed to have been caused by the humidity regulation effect of SAP.

In the case of the mixture with both SAP and SRA, the slope of the behavior curve was more moderate due to the effect of SRA. The shrinkage reduction compared with OPC was found to be approximately $49 \%$ at the surface and $69 \%$ in the middle, resulting in greater shrinkage reduction compared with the mixture with only SAP added.

The CSA mixture exhibited a lower shrinkage compared with the OPC. We presume that this occurred due to the expansion behavior in accordance with the initial ettringite production partially offsetting the shrinkage. However, the CSA mixture still had a lower shrinkage reduction rate than the SAP mixture, and SAP is likely to be more effective overall considering the quantity of the input materials and unit costs. Comparing the results of the CSA + SRA and CSA + SAP mixtures, we found that the SAP was more effective in reducing shrinkage compared with the SRA. In particular, the addition of both CSA clinker and SAP exhibited a tendency for relatively large initial expansion behavior, resulting in a significant reduction in overall shrinkage with the shrinkage reduction rate being approximately $70 \%$ in the middle of the concrete.

When the CSA clinker, SAP, and SRA reviewed in this study were all added together, the middle shrinkage became approximately $-19 \mu \varepsilon$ after 80 days. Thus, we believe that we can manufacture a long-term non-shrinkage concrete. In addition, the CSA + SAP + SRA mixture was evaluated to have the best shrinkage reduction effect among all the tested mixtures, with the shrinkage reduction being approximately $78 \%$ at the surface and $96 \%$ in the middle compared with OPC.

When we analyzed the difference in shrinkage between the surface and middle of the concrete with and without SAP added, the difference for the OPC mixture was approximately $73 \mu \varepsilon$ on the third day, while that of the SAP mixture was $0 \mu \varepsilon$. That on 80 th day was approximately $133 \mu \varepsilon$ for the OPC mixture, while it was $86.2 \mu \varepsilon$ for the SAP mixture. This means that SAP reduced the difference in shrinkage between the surface and middle, thereby increasing the volume stability of the hardened concrete. However, this effect was not observed when other additives were used in addition to the SAP.

\section{Conclusions}

In this study, we evaluated the strength and shrinkage properties of concrete with three additives: SAP, CSA clinker, and SRA. For the shrinkage tests, we modified the typical autogenous shrinkage test method by leaving the concrete surface uncovered (instead of covering it with polyester film) and allowing moisture to evaporate from the surface. We then monitored the shrinkage behavior over a period of 80 days.

The main conclusions drawn from this study are as follows:

- $\quad$ The compressive strength of the concrete mixture with $10 \%$ CSA clinker added was found to be greater by approximately $8 \mathrm{MPa}$ compared with the OPC mixture after one day of aging. It also exceeded $21 \mathrm{MPa}$ at the end of day one, easily meeting the requirements for traffic-opening in Korea.

- In the mixture with SAP added, the compression strength tended to decrease slightly. Given that various conclusions have been drawn in preceding studies, we believe that the impact of the internal curing effect of SAP on concrete strength remains unclear.

- Comparing concrete shrinkage properties over the first $72 \mathrm{~h}$, the mixtures using SAP or SRA were found to have strains of almost $0 \mu \varepsilon$, while the middle shrinkage of the OPC mixture was approximately $-270 \mu \varepsilon$. Thus, we presume that SAP and SRA are effective in reducing initial shrinkage. In the case of the mixture with CSA, the 
compensation effect caused by the initial expansion behavior resulted in a reduction of approximately $50 \mu \varepsilon$ compared to the OPC, which was not significant compared with the effect of SAP and SRA.

- The initial expansion behavior when adding CSA and SAP was relatively large, and the expansion remained until after $72 \mathrm{~h}$. We estimate that the internal humidity regulation effect of SAP increased the reactivity of CSA, though further analysis would be needed to confirm this.

- In analyzing the concrete shrinkage behavior of each different mixture over 80 days, we found that SAP and SRA had stronger shrinkage reduction effects than CSA. When SAP and SRA were used together, the shrinkage reduction rate compared with OPC was approximately $69 \%$. Additionally, the mixture of CSA, SAP, and SRA led to a middle shrinkage strain of approximately $-19 \mu \varepsilon$, indicating it would be possible to further maximize the shrinkage reduction effect.

- Analyzing the strain data at the surface and in the middle of the concrete during the shrinkage tests, using SAP alone was found to reduce the difference in shrinkage between the surface and the middle. Thereby, we found that it was possible to improve the volume stability of the hardened concrete. However, this effect was not observed when other additives were included with the SAP.

Author Contributions: Conceptualization, S.-I.J. and J.-M.N.; methodology, D.-H.J.; software, J.-M.N.; validation, S.-I.J. and D.-H.J.; formal analysis, J.-M.N.; investigation, D.-H.J.; resources, S.-I.J.; data curation, D.-H.J.; writing—original draft preparation, S.-I.J.; writing—review and editing, D.-H.J.; visualization, D.-H.J.; supervision, J.-H.N.; project administration, J.-H.N. All authors have read and agreed to the published version of the manuscript.

Funding: This study was carried out as a part of the "Development of high-performance concrete pavement maintenance technology to extend roadway life (20POQW-B146707-03)" research task funded by the Korea Agency for Infrastructure Technology Advanced. The research support is greatly appreciated.

Institutional Review Board Statement: Not applicable.

Informed Consent Statement: Not applicable.

Data Availability Statement: Not applicable.

Acknowledgments: We conducted this study with research support from the Ministry of Land, Infrastructure and Transport, and the Korea Agency for Infrastructure Technology Advancement under the traffic and distribution project "Development of high-performance concrete pavement maintenance technology to extend roadway life (20POQW-B146707-03)". We express our gratitude to everyone involved.

Conflicts of Interest: The authors declare no conflict of interest.

\section{References}

1. Imbabi, M.S.; Carrigan, C.; McKenna, S. Trends and developments in green cement and concrete technology. Int. J. Sustain. Built Environ. 2012, 1, 194-216. [CrossRef]

2. Hooton, R.D.; Bickley, J.A. Design for durability: The key to improving concrete sustainability. Constr. Build. Mater. 2014, 67, 422-430. [CrossRef]

3. MOLIT. Overall Road Pavement Maintenance Cost. 2020. Available online: http://www.rsis.kr/maintenance_profit_summary. htm (accessed on 7 June 2021).

4. Kosmatka, S.H.; Wilson, M.L. Design and Control of Concrete Mixture, 15th ed.; PCA (Portland Cement Association): Skokie, IL, USA, 2011; pp. 304, 307.

5. Kohno, K.; Okamoto, T.; Isikawa, Y.; Sibata, T.; Mori, H. Effects of Artificial Lightweight Aggregate on Autogenous Shrinkage of Concrete. Cem. Concr. Res. 1999, 29, 611-614. [CrossRef]

6. Jensen, O.M.; Hansen, P.F. Water-Entrained Cement-Based Materials. Cem. Concr. Res. 2001, 31, 647-654. [CrossRef]

7. Mechtcherine, V.; Reinhardt, H.W. Application of Superabsorbent Polymers (SAP) in Concrete Construction; 225-SAP; RILEM (International Union of Laboratories and Experts in Construction Materials, Systems and Structures): Geneva, Switzerland, 2012; pp. 23-30. ISBN 978-94-007-2732-8. 
8. Laustsen, S.; Hasholt, M.T.; Jensen, O.M. A New Technology for Air-Entrainment of Concrete. In Proceedings of the 1st International Conference on Microstructure Related Durability of Cementitious Composites, Nanjing, China, 13-15 October 2008; RILEM (International Union of Laboratories and Experts in Construction Materials, Systems and Structures): Geneva, Switzerland, 2008; Volume 61, pp. 1223-1230.

9. Lee, H.X.D.; Wong, H.S.; Buenfeld, N.R. Self-Sealing of Cracks in Concrete Using Superabsorbent Polymers. Cem. Concr. Res. 2016, 79, 194-208. [CrossRef]

10. Kanellopoulou, I.A.; Kartsonakis, I.A.; Charitidis, C.A. The Effect of Superabsorbent Polymers on the Microstructure and Self-Healing Properties of Cementitious-Based Composite Materials. Appl. Sci. 2021, 11, 700. [CrossRef]

11. Han, J.; Fang, H.; Wang, K. Design and Control Shrinkage Behavior of High-Strength Self-Consolidating Concrete Using Shrinkage-Reducing Admixture and Super-Absorbent Polymer. J. Sustain. Cem. Based Mater. 2014, 3, 182-190. [CrossRef]

12. Liu, J.; Farzadinia, N.; Shi, C.; Ma, X. Shrinkage and strength development of UHSC incorporating a hybrid system of SAP and SRA. Cem. Concr. Compos. 2019, 97, 175-189. [CrossRef]

13. Roh, J.M.; Jeon, S.I.; Jeong, J.H. Strength and Durability of Concrete according to Internal Curing Method. Int. J. Highw. Eng. 2021, 23, 1-9. [CrossRef]

14. Bentz, D.P.; Geiker, M.; Jensen, O.M. On the Mitigation of Early Age Cracking. In International Seminar on Self-Desiccation and Its Importance in Concrete Technology; Lund University: Lund, Sweden, 2002; Volume 15, pp. 195-204.

15. Gao, D.; Heimann, R.B.; Alexander, D.B. Box-Behnken Design Applied to Study the Trengthening of Aluminate Concrete Modified by a Superabsorbent Polymer/Clay Composite. Adv. Cem. Res. 1997, 9, 93-97. [CrossRef]

16. Ding, H.; Zhang, L.; Zhang, P. Factors Influencing Strength of Super Absorbent Polymer (SAP) Concrete. Trans. Tianjin Univ. 2017, 23, 245-257. [CrossRef]

17. Péra, J.; Ambroise, J. New Applications of Calcium Sulfoaluminate Cement. Cem. Concr. Res. 2004, 34, 671-676. [CrossRef]

18. Geiker, M.R.; Bentz, D.P.; Jensen, O.M. Mitigating Autogeneous Shrinkage by Internal Curing; ACI Fall Convention; American Concrete Institute: Detroit, MI, USA, 2002; pp. 143-154.

19. Geiker, M.R.; Bentz, D.P.; Jensen, O.M. Mitigating Autogenous Shrinkage by Internal Curing. ACI Special Publ. 2004, $218,143-148$.

20. He, Z.; Chen, X.; Liang, W. Effect of Internal Curing on Shrinkage and Cracking of Concrete. New Build. Mater. 2008, 8, 640. (In Chinese)

21. Mechtcherine, V.; Gorges, M.; Schroefl, C.; Assmann, A.; Brameshuber, W.; Ribeiro, A.B.; Cusson, D.; Custódio, J.; Da Silva, E.F.; Ichimiya, K.; et al. Effect of internal curing by using superabsorbent polymers (SAP) on autogenous shrinkage and other properties of a high-performance fine-grained concrete: Results of a RILEM round-robin test. Mater. Struct. 2014, 457, 541-562. [CrossRef]

22. Wang, L.; Liu, N.; Li, J. SAP Role on the Improvement of the Early Cracking of Concrete in Hot and Dry Environment. Concrete 2014, 2, 50-53. (In Chinese)

23. Yoo, D.Y.; Park, J.J.; Kim, S.W.; Yoon, Y.S. Evaluating Early Age Shrinkage Behavior of Ultra High Performance Cementitious Composites (UHPCC) with CSA Expansive Admixture and Shrinkage Reducing Agent. J. Korea Concr. Inst. 2011, 23, 441-448. [CrossRef]

24. Jeon, S.I. Self-Healing and Shrinkage of Ternary Blended Concrete with Expansion Agent. Ph.D. Thesis, Kangwon National University, Chuncheon, Korea, 2016; pp. 134-139. (In Korean) 